\title{
KNOWLEDGE OF SEXUALLY TRANSMITTED DISEASES STDS IN KADUNA METROPOLITANTS, NIGERIA
}

\author{
Hadiza Tukur A., PhD \\ Aisha Indo Mohammed, PhD \\ Umma Abdulwahid, PhD \\ Umaru Y., PhD
}

Department Of Educational Psychology And Counselling, Faculty Of Education, Ahmadu Bello University, Zaria

\begin{abstract}
The study employed survey design in investigating the knowledge of the Sexually Transmitted Diseases STDs in Kaduna metopolitant, Kaduna State, Nigeria. A Sample of 237 (caregivers and adolescents) was used for this study. Four research questions and four null hypotheses were formulated. Statistical means was used to answer the research questions and t-test was used in testing the null hypotheses. The results show that: caregivers and adolescents know very little about the forms of STDs, the students have moderate knowledge of the signs and symptom of various STDs, male and female caregivers had agreed with mode of transmission, and the control measures toward STDs. Based on the above findings recommendations were made among which are: School Psychologists, counsellors should continuously sensitize the caregivers and adolescents, and organize group guidance programme in school on personal health and risky behaviour, and there should be synergy between health twisters, school administrators and parents in creativity awareness among caregivers and adolescents on the risk factors, symptom and control of STDs, and voluntary HIV test before marriage, poverty alleviation programme to re address the epidemics among others are made.
\end{abstract}

Keywords: Knowledge of Sexually Transmitted Diseases (STDs), Forms, Symptom, Mode of Transmission, Control, Caregivers and Adolescents. 


\section{Introduction}

Adolescent has been described by Coleman and Hendry (1990) as a period of experimentation. According to them, one of those issues adolescents experiment on is sex. This explains, perhaps, why UNICEF (2004) noted that adolescents are the most heterosexually active cohort the world over. Similar sentiments (Ezedum 2000, Oluwole, 2008) have been shared in Nigerian concerning the Nigerian adolescent. Erickson (1968) as cited in Okoye (2003) maintained that the hazard of adolescent is role confusion / search for personal identity. During these period adolescents encounter such problem like falling in love with opposite sex and changes in their physical features (males and females alike) which may knowingly a unknowingly lead to teenage pregnancy, abortion and its complications, prostitution, sex abuse and sexual violence, and the spread of sexually transmitted diseases (STDs) including Human Immuno-deficiency Virus/Acquired Immuno-deficiency Syndrome (HIV/AIDS). All of these do affect school programs and sometimes even lead to dropping out of school of Nigerian youths, which by implication influence the development of the nation.

Acquired Immune Deficiency Syndrome (AIDS) is a serious and deadly disease caused by the virus that attacks and destroys the body defense system, thereby leading the body defenseless (Unachukwu, 2003). The body becomes open to infection and diseases which the body could normally fight off, it is becoming obvious that AIDS possess a serious health problems in Africa. Obekeze (1997) state that AIDS is the greatest scourge of modern times, thus it is the most important new threat to the world health body and has no cure Since its discovery in the early 1980s, HIV/AIDS has become a pandemic on a global scale. It is no longer only health issue but a substantial threat to economic growth and development, imposing a heavy burden first on families, then on communities and eventually economics. The impact of the pandemic is already being felt in most countries of the world. An estimate of 11 persons became pandemic is already minute representing some 15,000 new infections every day or more than 5.4 million for the entire year (WHO, 2000). Similarly, the Joint United Nations Programme on HIV/AIDS (UNAIDS) estimated that as at 2003, about 38 million persons were HIV positive worldwide and almost 26 million were workers between 15 and 49 years, and of the 2.9 million HIV/AIDS related deaths in 2003, 2.2 million were from Sub-Saharan Africa. While the Sub-Saharan Africa region contain only 10 percent of the world's population, it accounts for 60 percent of the worldwide HIV/AIDS cases (UNAIDS Africa Fact Sheet, 2004). This implies that the most productive age group is mostly affected and this has implications for families and economics in terms of income, employment and labour market changes. 
Nigeria, the most populous country in Africa with a population estimate of about 140 million in 2006 (NPC, 2007), is fast gaining its share of the HIV/AIDS scourge. Nigeria has the highest prevalence rate in West African Sub-region and the third highest prevalence of any country in the world with a five percent population prevalence rate, that is, over 3.6 million people (UNAIDS/WHO, 2004). The widespread and rising HIV/AIDS is a problem that could be affecting the growth of the Nigerian economy which, led to compounding poverty, low standard of living, low productivity, increased unemployment, morbidity and mortality rates and ultimately obstruct development efforts. Thus, with the alarming growth of the disease within the country, the study is concern with the possible effects of HIV/AIDS on economic growth in Nigeria and the extent to which various polices can alter them (Maijama’a \& Muhammad, 2013).

However, the situation in developing countries shows that the diseases occur predominantly in the heterosexual populations, and therefore, heterosexual contact in these areas is considered a major risk factor of infection. Besides, the disease has been observed in intravenous drug abusers, hemophiliacs, and recipients of blood transfusion or blood products. Some cases of AIDS originating from organ transplantation have been recorded. For Achalu (1993) AIDs is a group of diseases that result from the infection with the AIDS virus.

The traditional values among Nigerian for sanctity of sex and sex for procreation have been over thrown in favour of liberal sexual behaviors. There is evidence of high risk of sexual behaviour and premarital sexual involvement among Nigerian adolescents (Unachukwu and Nwankwo, 1998). The commonest STDS include HIV/AIDS, Trichomoniasis, General Warts, Syphilis, Herps, Genitalia Tines Crunus, Scabies and Gardenerella Veginalis. Others are Hypphorgramutoma, Verecem, Choncroid and Vereophobia (Nnankwo, 2003). the tragedy of the premarital sexuality among adolescents is that they engage in frequent sexual activities without proper knowledge of what is involved (Obikeze, 1997). Achalu (1996) maintained that, those who engage in high risk behaviors such as indiscriminate sex with many partners or those who take partners from the streets have increased chance of being infected. Owolabi (1985) emphasized that, sexual practices such as anal intercourse, oral intercourse, homosexuality and deep kisses are associated with high risks of contacting these diseases especially the Virus that causes AIDS. Furthermore, Owolabi (1985) noted that some of the prevalence of STDS in Nigeria is due to sexual promiscuity, prostitution, and homosexuality, lack of sex education, self medication and drug abuse among others. Adolescents especially those in secondary schools are among the most sexually active segment of the population. They are also more likely to engage in risky sexual practices that 
increase the chances of infections (Hopkins, 1998). AIDS have causes a number of complications including abortions, premature birth, blindness, infertility, heart and mental diseases, bone disorders, and so on. Effort to reduce the problem in controlling the diseases among patients who do not go to doctors at the early stage of the diseases due to stigma attached to the disorder related to sex organ. In spite of the modern medicine, STDS have become very difficult to control largely because people seem not to know the truth about them.

\section{Related literature}

Unachukwu (2003) investigated that, the level of awareness on the aetiology, and clinical pictures of HIV/AIDS among adolescents. The research was carried out in Anambra State. The population was about 20 thousand students in the secondary schools in the urban and rural locations in the State. Then, 2500 SS1 and SS2 adolescents were used as sample. They were selected through multiphase sample techniques. Their schools were selected through simple random sampling, while 100 students were used from each of the 25 selected schools. They were however, chosen from SS1 and SS2 classes. The instruction for data collection was QAAECA. Direct approach was used in teir administration by the help of research assistants. Statistical mean was used in answering the research questions. The finding showed that the adolescents are lacking the knowledge of the aetioloby, epidemiology and clinical pictures of HIV/AIDS.

Nwachukwu (2003) investigated that the knowledge and attitude of secondary school students towards sexually transmitted disease in Anambra State. A sample of 2500 SSII students made up of 1450 girls and 1050 boys was used. A questionnaire titled QSKATSTD was developed, structured and validated. Four research questions and two null hypotheses were formulated for the study. Statistical weighted mean was used to answer the research questions and t-test was adopted in testing the null hypotheses. The result showed that: the students know very little about the forms of STDs, the students have poor knowledge of the signs and symptoms of various STDs, the students know little about the modes and of control of transmission, the students have very poor attitude towards STDs, there is, however, significant difference in the boys and girls knowledge and attitude towards STDs,

Maijama'a and Muhammad (2013) investigated that, the impact of HIV/AIDS on economic growth and development in Nigeria using primary and time series data. It also looked at the effect of the epidemic on savings and standard of living. To obtain the primary data, a total of 360 respondents comprising 180 persons infected with HIV/AIDS and 180 uninfected persons were selected sing stratified sampling technique. The primary data was analyzed using frequencies, percentages and chi-square test. In analyzing the 
time series data, a Solow-type growth model is extended to incorporate some of the macroeconomic consequences of HIV/AIDS. Using this model, co integration and error correction modeling techniques were adopted to examine the relationship between the variables. The findings show that HIV/AIDS prevalence is widely spreading and rapidly rising and has a negative impact on Real GDP growth in Nigeria. Also, recurrent health expenditure does not appear to be growth augmenting during the period HIV/AIDS was also found to adversely affect savings and standard of living of infected persons.

Anagbogu (2003) investigated that, examined adolescents’ perception of HIV/AIDS symptoms as sources of early death among Nigerian youths. A total of 100 male and female students were randomly chosen from ten schools located at old Oyi local government area of Anambra State. A questionnaire on HIV/AIDS symptoms was administered. The findings of the study indicated that the adolescents do not associate high death rate of youths with HIV/AIDS symptoms. The study further showed that the youths associate high death rate with witchcraft and evil practice in the Nigerian society. Unfortunately, the youths are the view that HIV/AIDS is one of the techniques with witchcraft society utilized in destroying the Nigeria youths.

\section{Objectives of the study}

The objectives of this study include:-

- To determine the level of awareness of different forms of STDS as perceived by the Caregivers and the Adolescents.

- To find out the extent do Caregivers and Adolescents knows the signs and symptoms of STDS.

- To determine the mode of transmission of STDs as perceived by the Caregivers.

- To examine the Caregivers' levels of knowledge of control measure of STDs.

\section{Research Questions}

The following research questions guided this study:

- What is the level of awareness of different forms of STDS as percieved by the Caregivers and Adolescents?

- To what extent do Caregivers and Adolescents knows the signs and symptoms of STDS?

- What is the mode of transmission of STDs as perceived by the Caregivers?

- What are Caregivers' levels of knowledge of control measure of STDs? 


\section{Research Hypotheses}

The following null hypotheses were stated for this study:

- Caregivers and Adolescents will not differ significantly on their measures of awareness of various forms of STDs.

- Caregivers and Adolescents will not differ significantly on their mean score of Symptoms and Sign of STDs.

- Male and female Caregivers will not differ significantly on the mode of transmission of STDs.

- Male and female Caregivers' will not differ significantly on the levels of knowledge of control measure of STDs.

\section{Methodology}

The study is a survey design meant to seek data on the knowledge of the subjects on sexually transmitted diseases. A sample of 237 respondents made up of 105 Caregivers and 132 Adolescents in Kaduna metropolitan, Kaduna State , Nigeria were used for the study. Simple random sampling technique was used in selecting the subjects. The researcher made use of questionnaire tagged; Awareness of forms, symptoms, mode of transmission and control (AFSTC) of STDs. It was structured on four (4) point Likert scale items and divided into four sections A, B, C, D and validated by three experts in Psychology, Medicine and Measurement and Evaluation. Their contribution led to the dropping and addition of some items. Also to determine the reliability of the instrument, it was giving to 50 caregivers and students in SS II in Katsina State, Cronbach alpha was used in the analyses. Which yielded the coefficient alpha for the four sections was $0.76,0.72,0.82$ and 0.85 respectively. The researcher employed the service of research assistants in collecting the data which was done through direct delivery approach. The data collected were collated and analyzed, using statistical means for the research question and t-test to test the null hypotheses (a cut of point of 2.50 indicate acceptance level while below indicate rejection of the items by the respondent).

\section{Results}

The results of the study were presented in tables based on the research questions and the null hypotheses formulated to guide this study.

Research Question 1: What is the level of awareness of different forms of STDS by the Caregivers and Adolescents?

Table.1: The mean responses of Caregivers and Adolescents of the awareness of different forms of STDS

\begin{tabular}{|c|c|c|c|}
\hline Respondents & $\mathrm{N}$ & $\bar{X}$ & SD \\
\hline Caregivers & 105 & 2.68 & 0.608 \\
\hline Students & 132 & 2.89 & 0.643 \\
\hline
\end{tabular}


Table .1 Shows that both caregivers and adolescents agreed conveniently to the perceived level of awareness of STDs. This is evident from the mean score of 2.68 for caregivers and 2.89 for adolescents with SD of 0.608 and 0.643 respectively, which are all above the criterion mean of 2.5. in the Table, the mean score of the adolescents was slightly higher than that of caregivers.

Question 2: To what extent do caregivers and adolescents knows the signs and symptoms of STDS?

Table 2: Mean responses of caregivers and adolescents on the extent of the signs and symptoms of STDs.

\begin{tabular}{cccc}
\hline Respondents & $\mathrm{N}$ & $\bar{X}$ & $\mathrm{SD}$ \\
\hline caregivers & 105 & 3.22 & 0.297 \\
Students & 132 & 3.19 & 0.298 \\
\hline
\end{tabular}

Table. 2 shows that both caregiver and adolescents, agreed with the signs and symptoms of STDs. That is evident from the mean score of 3.22 and 3.19, with SD of 0.297 and 0.298 of caregiver and adolescents respectively, which are above the criterion mean of 2.5 in the Table; the mean score of caregivers was slightly higher than that of the adolescent counterparts.

Question 3: What is the mode of transmission of STDs as perceived by the caregivers?

Table.3: The mean responses of male and female caregivers on the mode of transmission of STDs.

\begin{tabular}{|c|c|c|c|}
\hline Gender & $\mathrm{N}$ & $\bar{X}$ & SD \\
\hline Male & 74 & 2.86 & 0.520 \\
\hline Female & 31 & 4.77 & 0.583 \\
\hline
\end{tabular}

Table 3 Shows that, both male and female caregivers agreed with the on the mode of transmission of STDs. This is evidential from the mean score of 2.86 with SD of 0.520 and 4.77 with SD of 0.583 for both male and female caregivers respectively, which is above the criterion mean of 2.50. In the Table, the scores of female caregivers was slightly higher than that of their male counterparts. This shows that, caregivers are aware of only very few signs and symptoms of the venereal diseases of STDs.

Research Question 4: To examine the caregivers' levels of knowledge of control measure of STDs.

Table.4 the mean responses of male and female caregivers on the levels of knowledge of control measure of STDs.

\begin{tabular}{llll}
\hline Gender & $\mathrm{N}$ & Mean & SD \\
\hline Male & 74 & 2.84 & 0.501 \\
Female & 31 & 3.27 & 0.197 \\
\hline
\end{tabular}


From Table .4 shows that both male and female caregivers conveniently agreed with the level of knowledge of control measure of STDs. This is evident with a mean score of 2.84 and 3.27 (both male and female) respectively, with SD of 0.501 and 0.197 ; which is above the criterion mean of 2.50 the mean score of female caregivers was slightly higher than that of their male counterparts.

Hypothesis one: Caregivers and Adolescents will not differ significantly on their measures of awareness of various forms of STDs.

Table 5:Independent t-test statistics on difference between Caregivers and Adolescents on various forms of STDs.

In Table 5 it was observed that the calculated t. value of 15.85 is greater than the critical t. value of 1.96 and 0.05 alpha level of the null hypothesis is rejected. This means that the Caregivers and Adolescents will not differ significantly on their measures of awareness of various forms of STDs, in favour of the caregivers .

\begin{tabular}{cccccccc}
\hline Group & $\mathbf{N}$ & $\bar{X}$ & SD & Df & t-cal & t-crit & Decision \\
\hline caregivers & 105 & 7.63 & 1.103 & & & & \\
Student & 293 & 5.57 & 1.251 & 396 & 15.85 & 1.96 & Rejected \\
\hline
\end{tabular}

Hypothesis Two: Caregivers and Adolescents will not differ significantly on their mean score of Symptoms and Sign of STDs.

Table 6: Independent t-test statistics on Caregivers and Adolescents will not differ significantly on their mean score of Symptoms and Sign of STDs.

\begin{tabular}{cccccccc}
\hline Respondent s & $\mathbf{N}$ & $\bar{X}$ & SD & Df & t-Cal & t-Crit & Decision \\
\hline Caregivers & 105 & 6.11 & 0.698 & & & & \\
Adolescents & 293 & 6.41 & 0.595 & 396 & 3.92 & 1.96 & Rejected \\
\hline
\end{tabular}

Table 6 also rejected that the calculated value of 3.92 is greater than the critical t-value of 1.96 and 0.05 alpha level. This means that Caregivers and Adolescents will not differ significantly on their mean score of caregivers.

Symptoms and Sign of STDs. But this was in favour of the

- Hypothesis Three: Male and female caregivers will not differ significantly on the mode of transmission of STDs.

Table 7: Independent t-test statistics on Male and female caregivers will not differ significantly on the mode of transmission of STDs.

\begin{tabular}{cccccccc}
\hline Caregiver & $\mathbf{N}$ & $\bar{X}$ & SD & Df & t - cal & t-crit & Decision \\
\hline Male & 74 & 2.86 & 0.517 & & & & \\
Female & 31 & 2.82 & 0.583 & 103 & 0.33 & 1.96 & Accepted \\
\hline
\end{tabular}


Table 7 shows that the calculated t-value of 0.33 is less than the critical t-value of 1.96 and 0.05 alpha level. The null hypothesis is thereby accepted. This means that Male and female caregivers will not differ significantly on the mode of transmission of STDs.

Hypothesis four: Male and female caregivers will not differ significantly on the levels of knowledge of control measure of STDs.

Table 8: Independent t-test statistics on male and female caregivers will not differ significantly on the levels of knowledge of control measure of STDs.

\begin{tabular}{lccccccc}
\hline Caregiver & $\mathbf{N}$ & $\overline{\mathbf{X}}$ & SD & Df & t-cal & t-crit & Decision \\
\hline Male & 74 & 2.84 & 0.501 & & & & \\
Female & 31 & 3.27 & 0.197 & 103 & 6.32 & 1.96 & Rejected \\
\hline
\end{tabular}

Table 8 also shows that the calculated t-value of 6.32 is greater than the critical t-value of 1.96 and 0.05 alpha level. The null hypothesis is thereby rejected. This means that male and female caregivers will not differ significantly on the levels of knowledge of control measure of STDs, but in favour of the female caregivers.

\section{Discussion}

The finding reveals that no significant differences exist between caregivers and adolescents on knowledge of the various forms, sign and symptoms of sexually transmitted diseases. This findings is in line with the early finding of Achalu (1996),Unachukwu(2003), and Anagbagu(2003), maintained the adolescents do not associate high death rate of youths with HIV/AIDS symptoms. The study further showed that the youths associate high death rate with witchcraft and evil practice in the Nigerian society. Unfortunately, the youths are the view that HIV/AIDS is one of the techniques with witchcraft society utilized in destroying the Nigeria youths.Evidence has shown that most students continue to regard STDs wrongly as a moral rather than medical problem. The psychological nature of the disease and the fact that these STDs are contact mainly through intimate sexual contacts with infected individuals has made it one of the most feared diseases known to man. But the attitudes towards sex and the wide spread ignorance about STDs, the rate of the spread has become a syndrome (Hopkins, 1998 \& Myles 2001).

Furthermore, this study revealed that no significant differences on the mode of transmission , and control measures of sexually transmitted diseases as perceived by the male and female caregivers.

This could be the more reason why the present day adolescents have more liberal and permissive attitudes and behaviors towards premarital sex. Achalu (1996) emphasize those who engage in high risk behaviors such as indiscriminate sex with many partners or those who take partners from the 
streets have increase chances of being infected (Hopkins, 1998).STDs are not just health related problems, but constitutes social problems, with grave consequences to the individual and the society at large. Unackwuku and Nwanko (1988) maintained that the disease can lead to pains, discomfort, physical disabilities, mental and emotional suffering and in some cases, death. Young students are extremely at risk of acquiring and transmitting STDs because of the sexual behavior, which from this study lacks the full knowledge of what STDs (Nwankwo, 2003) measures to include proper medication social re-orientation, proper sensitization and a change in the attitudes of the secondary school students towards STDs and sexuality related problem of students should be emphasized (Maijama'a \& Muhammad, 2013; Owolabi 1985; Unachukwu ,2003).

\section{Conclusion}

Based on the findings of this study it can be deduce that, there is very high risk of spread of STDs among young persons in the society, but the present studies will help the caregivers and adolescents to be aware of various forms, signs, symptoms, mode of transmission and control STDs. There is therefore, an urgent need for responsive Counselling services in Nigeria schools and the society at large.

\section{Recommendations}

From the finding of this study, the following recommendations are made:

1. School Psychologist and counsellors should organize group guidance programme for caregivers and adolescents in school system, churches and recreational centre with the aim of educating young people about STDs. The content of the programme should be ways to reduce the risk of STDs.

2. Voluntary HIV Test before marriage should be emphasized.

3. Expansion of Anti-Retroviral Drugs (ARD) should made available s to HIV patient.

4. Government should introduce programme to reduce poverty at individual family as well as community levels such programme should include home base care for people with HIV/AIDS, foster care for AIDS orphans, food programme for the children and support for educational experience.

5. Sex education should be build into school curriculum in senior secondary school classes (SSS I-III). To include:

$\checkmark$ To inform people and to help them make intelligent decisions and take actions that will improve or promote health,

$\checkmark$ To enlighten the public about the problems of STDs. 
$\checkmark$ To secure support for STDs control.

$\checkmark$ To educate people about the risk factors contributing to STDs.

$\checkmark$ To encourage people to avoid or reduce the risk of infection.

6. Psychologist and Counsellors should always organize group guidance services on healthy leaving were they will be educating the adolescents on the risk behaviours and their consequences as well as predisposing factors.

7. Federal and state governments should assist the psychologist and Guidance and Counsellors in providing pamphlets and printed materials on STD and HIV/AIDS education.

\section{Suggestions}

Further studies should be geared towards adolescent perception of mode of transmission and control of STDs in Nigeria and rest of Africa in general.

\section{Reference:}

Achalu, L. E. (1993). AIDS and other Sexually Transmitted diseases, Lagos: Simarch Nig. Ltd.

Achalu, L. E. (1996). AIDS: How to protect yourself and family signs and symptoms, Lagos: Simarch Nig. Ltd.

Anagbogu, M. A. (2003). Adolescent Perception of HIV/AIDS Symptoms in Oyi Local Government Area. The Educational Psychologist, 2003,1(1): 104125

Coleman, J.C. \& Hendry, L.(1990). The Nature of Adolescent. London. Rutledge.

Erikson, A.H. (1968). Identify, Youth and Crisis. New York Norton and Company. Ezedum, C.E (2001) Influence of Age on Aids-Related Heterosexual Behaviour Patterns of Students in Anambra state Secondary School. Unpublished Manuscript.

Ezedum, C.E (2001) Influence of Age on Aids-Related Heterosexual Behaviour Patterns of Students in Anambra state Secondary School. Unpublished Manuscript.

Hopkins, J. (1998). The essentials of contraceptive technology. Beltimore: John Hopkins University, school of health.

McSweeney, L. (2001). AIDS your Responsibility, Ibadan: Ambassador Publications.

Myles, Mr. (2001) a Textbook for midwives $\left(13^{\text {th }}\right.$ ed.) China: Harcort brace and com. Ltd.

Maijama'a D. \& Muhammad B. K. (2013). Impact of HIV/AIDS on Economic Growth and Development in Nigeria. international Journal of 
Basic and Applied Science. Inasn Akademika Publications. Retrieved on 28/12/13 at www..insikapub.com

Nwachukwu C. A. (2003). Knowledge and Attitude of Secondary School

Students Towards Sexually Transmitted Disease in Anambra State: the educational psychologist, 2003, 1(1): 75-88

National Population Commission (2007). National and State Population

Projections, 2006 Population Census Analysis, Abuja. .

Obikeze, J. (1997). “AIDs Awareness Among Secondary Schools Students, Implication for Counselling in Anambra State. Journal for Counselling and Communications 10 (1): 77 - 82.

Oluwole, B.L. (2008) Perceived Causes of the Teenage Pregnancy among Secondary School Students in Ilorin Metropolis. Oro Science Educational Journal OSEJ Vol. 172 168-173.

Okoye R.C. (2007) Medical, Emotional and Social Challenges of Teenage Pregnancy Calabar. Save a Life Foundation Publisher.

UNAIDS/WHO (2004) "Epidemiological Fact Sheet on HIV/AIDS and SexuallyTransmitted Infections, Update”, Working Group on Global HIV/AIDS and STI Surveillance Unachuku, G.C. and Nwanko, C.A. (1998). " Parental Attitudes and the

Incidents of Early Sexual Activities: Implications for Counselling” Journal of CITADEL 2 (4): (152 - 167)

Unachukwu G. C (2003). Awareness of the Aetiology, Clinical Presentations and Epidemiology of HIV/AIDS, among Adolescents in Anambra State: the educational psychologist, 2003, 1(1): 23-26

UNICEF (2004) Adolescent Sexuality. The Facts. First call for children. July-September (3) 15

WHO (2000) "World Health Report: Health System Improving Performance”,WHO, Geneve. 